\title{
Article
}

\section{Health promotion and screening for people with an intellectual disability}

\author{
Awan, Hassan and Chauhan, Umesh \\ Available at http://clok.uclan.ac.uk/17724/ \\ Awan, Hassan and Chauhan, Umesh ORCID: 0000-0002-0747-591X (2017) \\ Health promotion and screening for people with an intellectual disability. \\ Innovait, 10 (3). pp. 157-164. ISSN 1755-7380
}

It is advisable to refer to the publisher's version if you intend to cite from the work. http://dx.doi.org/10.1177/1755738016682982

For more information about UCLan's research in this area go to

http://www.uclan.ac.uk/researchgroups/ and search for <name of research Group>.

For information about Research generally at UCLan please go to http://www.uclan.ac.uk/research/

All outputs in CLoK are protected by Intellectual Property Rights law, including Copyright law. Copyright, IPR and Moral Rights for the works on this site are retained by the individual authors and/or other copyright owners. Terms and conditions for use of this material are defined in the policies page.

\section{CLoK}

Central Lancashire online Knowledge www.clok.uclan.ac.uk

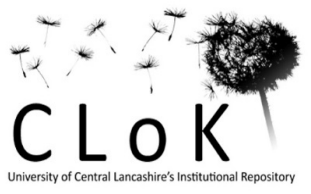




\section{Health promotion and screening for people with intellectual disability}

People with intellectual disability have significantly worse health than those without and have a higher level of complex health needs. The life expectancy for men and women is 13 and 20 years shorter respectively than the general population. The increasing role of general practice in delivering and coordinating care across health and social care settings requires expert generalist skills to implement an integrated approach to care. This article explores how general practice can improve the health of people with intellectual disability by making reasonable adjustments within health promotion, disease prevention, screening and detection.

\section{The GP curriculum and health promotion and screening for people with} intellectual disability

Clinical module 3.11: Care of people with intellectual disability. As a GP caring for people with intellectual disability, you should:

- Recognise the importance of the principle of fairness and equality, irrespective of the innate abilities of the individual

- Recognise that in every consultation you must make the effort to identify, monitor and review the progress of all persons who have difficulties with communication, social relationships and managing their own affairs

- Recognise that respect for diversity may involve challenging the values of the local community and society in general

- Be aware of the atypical morbidity and mortality prevalent in people with intellectual disability and the atypical presentation of acute and chronic physical and psychiatric disorders

- Be aware of the additional skills of diagnosis and examination needed in those who are unable to describe or verbalise symptoms and where to obtain specialist advice and help

- Be aware of the effects intellectual disability has on the life history of the person and family, particularly at times of transition

- Be aware of the effects intellectual disability has on the aging process, particularly in the development and recognition of dementia

- Understand the value of conducting regular (annual) health checks

Appreciate the role of your own practice population in the evolution of services for people with intellectual disability. All mainstream services should offer people with intellectual disability professional resources and facilities that are appropriate and tailored to their needs 
'Intellectual disability' is a term used to describe people with impaired intelligence and ability to understand and learn new information and skills: this is coupled with impaired social functioning and a reduced ability to live independently, which started before adulthood (Department of Health, 2001). Whilst 'intellectual disability' is used interchangeably with 'learning disability', the RCGP curriculum uses the term 'intellectual disability', as it is more precise and does not include specific learning difficulties, such as dyslexia or dyspraxia. Intellectual disability covers a wide range of abilities and disabilities, skills and limitations, ranging from mild to severe and profound.

\section{Epidemiology}

Common intellectual disabilities include Down's syndrome, Fragile X syndrome, cerebral palsy and certain autistic spectrum disorders. The prevalence of intellectual disability is approximately $3 \%$ of children and $2 \%$ of adults, although 3 in 4 adults with intellectual disability remain undiagnosed and are unknown to services (Emerson \& Hatton, 2004). In total, an estimated 1.2 million people in England have an intellectual disability (Emerson, Baines, Allerton \& Welch, 2012). Like the general population, people with intellectual disabilities are also living longer, with an associated risk of death from risk factors common within the general population.

\section{Health outcomes}

People with intellectual disability are more likely to suffer major illnesses and develop illness earlier: life expectancy for men and women is thirteen and twenty years shorter, respectively (Heslop et al., 2014). Compared to the general population, people with intellectual disability have higher overall levels of chronic disease, such as diabetes $(18.5 \%)$ and greater use of primary care (Carey et al., 2016). Obesity and respiratory disease are significant comorbidities, with obesity affecting up to $51 \%$ of people with intellectual disability compared to $29 \%$ of the general population (Stedman \& Leland, 2010) and respiratory disease affecting $19.8 \%$ compared with $15.5 \%$. The main cause of death is respiratory disease $(52 \%)$ related to pneumonia and aspiration. The Confidential Inquiry into the premature deaths of people with learning disabilities (CIPOLD) in 2014 found $42 \%$ of deaths to be premature. This was most commonly due to delays or problems with diagnosis or treatment and problems identifying needs and providing appropriate care in response to changing needs (Heslop et al., 2014).

\section{Uptake of screening}

Health promotion and screening are effective ways of improving health. Currently there are several health and screening programmes in the UK, but people with intellectual disability are much less likely to access such programmes. The main UK screening programmes are discussed below. 
Cervical screening in the UK offers 3-yearly smears for women aged 25-49 years, and 5-yearly from 50-64 years. An example of the inequality in uptake is that 84$89 \%$ of women in the general population are screened compared with $13-47 \%$ of eligible women with intellectual disability (Kerr et al., 2005).

Breast screening involves 3-yearly mammography for women aged 50-70 years, and is being extended to 75 years. There is evidence that women with intellectual disabilities are not well informed about breast cancer and that uptake of breast screening is low (Trusedale-Kenedy, Taggart \& Mcilfatrick, 2011; Emerson, Baines, Allerton \& Welch, 2012). In 2009, women with an intellectual disability were $35 \%$ less likely to attend for mammography than those without (Osborn et al., 2012).

Bowel screening involves testing faecal samples for occult blood every 2 years for men and women aged 60-74 years. Risk factors for bowel cancer include being overweight, having a poor diet, and not taking enough exercise, which all put people with intellectual disabilities at higher risk. Rates of death from gastrointestinal cancer are higher in this population at 48\%-59\% compared to $25 \%$ of cancer deaths in the general population (Emerson, Baines, Allerton \& Welch, 2012). The current method for inviting the population to take part does not take into account the need to provide accessible information for people with intellectual disability according to their need (e.g. easy-read/ audio/ video formats) or have a system in place for sharing information between bowel screening services and other health professionals involved in their care. Primary care is in a unique position to facilitate such screening programmes, by linking information on uptake of screening with prompts to support individuals at the practice level and also using their preferred method for communication.

Abdominal aorta aneurysm (AAA) screening is a relatively new programme, which involves an ultrasound scan for men aged 65 years or over. There is evidence that screening can reduce deaths from AAA by up to $50 \%$ (Thompson, Ashton, Gao \& Scott, 2009). Very little is known on the level of uptake in people with intellectual disability, but it is likely to be similar to other programmes and a structured approach should be taken to support those eligible.

Diabetic retinopathy (DR) screening is annual for all men and women with type 1 or 2 diabetes. DR is often asymptomatic during the early stages, but can be diagnosed and treated early through screening. There is very little evidence available on the prevalence of diabetes in people with intellectual disability, but it is likely to be higher (although may remain undiagnosed) due to the higher prevalence of underlying risk factors, such as obesity and sedentary lifestyle (Emerson, Baines, Allerton \& Welch, 2012).

\section{Barriers to healthcare}

There are a number of barriers to healthcare that people with intellectual disabilities face, which can result in poor health outcomes (Figure 1). These can be broadly related to individual health professionals' interpersonal skills or system-wide organisational deficiencies within healthcare. Institutional 
discrimination occurs when discrimination has been incorporated into the structures, processes and procedures of organisations, either because of prejudice or because of failure to take into account the particular needs of different social identities (London Deanery, 2012). There are insufficient checks and balances to challenge individuals or processes within the organisation, which result in unequal and unfair treatment. The cumulative effect of such unequal treatment can have a devastating effect, as highlighted by the Winterbourne View Hospital inquiry (Department of Health, 2012). System barriers include inflexible processes and administrative procedures e.g. inflexibility in booking appointments, little consideration to transport issues or adjustments to provision of information.

Health professionals may lack interpersonal skills and this can result in diagnostic overshadowing, when clinicians delay investigation or fail to appreciate symptoms by associating them with the intellectual disability (Mason \& Scior, 2004). Individual limitations may include poor communication skills, lack of clinical knowledge or confidence, time constraints and pessimistic views on outcomes and prognosis.

Insert figure 1 here

\section{Healthcare interactions}

\section{Individual/interpersonal adjustments}

Interpersonal skills are extremely important in managing people with intellectual disability. Perez (2002) gives ten top tips for effective consultations with someone with an intellectual disability (Box 1).

Insert box 1 here

\section{Capacity}

Judgement of capacity is an important part of consulting with and appropriately treating people with intellectual disabilities, in particular with regard to screening (Mental Capacity Act, 2005). Capacity assessment includes determining whether a person can understand information relating to a decision, retain it, weigh the information and communicate their decision. As per the principles of the Mental Capacity Act, capacity should be presumed unless proved otherwise. 'CURB' (Box 2) is a mnemonic developed to help doctors assess a person's capacity to make an appropriate decision (General Medical Council, 2016).

\section{Insert box 2 here}

People with intellectual disabilities should be supported to make their own decisions, if possible. A clinician can only decide that a person does not have capacity after taking all reasonable efforts to enhance capacity, such as employing easy-to-read information. Capacity is also decision-specific, so whilst 
someone with intellectual disability may not have capacity to make complex decisions about their care, their capacity should be assessed in relation to other decisions. If capacity is proved not to be present, then assessment should be made consistent with whatever is in the person's best interest. For any significant decisions when a person does not have capacity, they should be referred to an Independent Mental Capacity Advocate (IMCA), who provides independent support to the person to make their decisions.

\section{Equality}

It is unlawful for a service provider to discriminate against a disabled person and not provide a service that is offered to the public, thereby providing a lower standard of service and/or failure to make reasonable adjustments (Equality Act, 2010). The Equality Act goes on to describe 'indirect disability discrimination': when a rule or practice which, whilst applying to all, discriminates against people with a disability and is not justified to meet a legitimate aim in a fair, balanced and reasonable way. The Equality Act made reasonable adjustments compulsory when a disabled person experiences 'substantial disadvantage.' Reasonable adjustments are vast and varied, allowing room for organisational creativity. This may differ depending on locality and what works. They may include changing policies, practices and procedures, providing auxiliary aids and services, providing alternative services when usual service location is not accessible and removing, amending or avoiding physical barriers. As well as the adjustments discussed above, further examples are discussed as follows.

Longer appointment times for people with intellectual disability allow clinicians to go more at the pace of the individual and give more time in history- taking and explanation, if needed. This can be arranged easily, for example by adding a 'pop-up' to the clinical system, so that staff are prompted to book double appointments whenever clicking on the name of a person with intellectual disability.

The appointment of screening liaison nurses may be helpful: they are trained to help people with intellectual disability by liaison between the screening programmes and general practices, and to identify people with learning disabilities eligible for screening. Appointment of screening liaison nurses improved the breast screening uptake in one region from 36\% to 69\% (Turner, Giraud-Saunders \& Marriott, 2013).

\section{NHS health check}

The NHS health check is offered every 5 years to people aged 40 to 74 years to assess their cardiovascular risk factors, including blood pressure, body mass index and lipids. Cardiovascular disease is a leading cause of death amongst people with intellectual disabilities (Heslop et al., 2014). There is an opportunity to link prevention of these diseases to annual health checks for those aged 14 years and over with intellectual disability on the Quality and Outcomes Framework (QOF) register, which are currently part of an enhanced service with additional funding available to practices (NHS England \& BMA, 2015). 
Annual health checks for adults with intellectual disabilities have been shown to be effective in identifying new health needs (Buszewicz et al., 2014), providing an opportunity to review comorbidities e.g. epilepsy and diabetes, and offer health promotion e.g. access to dietary and smoking cessation services. Health checks are also important in young people with intellectual disabilities during the transition from childhood, through puberty and adolescence, to adulthood: they provide an opportunity to ensure coordination of care and that appropriate services continue from childhood into adulthood. This reduces loss to appropriate specialist follow-up.

Having a clinical lead for intellectual disabilities within the practice supports coordination and improves continuity of care: a structured team-approach is often required involving all members of the practice, with reasonable adjustments necessary by receptionists, clinicians and administrative staff in order to deliver health checks successfully. A multidisciplinary team approach involving the wider primary and community health care providers may also be needed to undertake health checks successfully. Despite $80 \%$ of practices offering health checks, less than $50 \%$ of people with intellectual disability currently receive health checks in England (Public Health England, 2014).

Adjustments to the administration of appointments to improve call and recall include individual telephoned appointment reminders (rather than sending letters), or the offer of health checks at home. It may be necessary to undertake blood tests a week beforehand: these may include a full blood count, C-reactive protein, urea and electrolytes, liver function tests, thyroid function tests, HbA1c (glycated haemoglobin), lithium monitoring if indicated, calcium and vitamin D if on anti-convulsant medication, follicle-stimulating hormone in a female with no period for 6 months, and a prostate-specific antigen may be considered in men over 50 years (Hoghton, 2010).

A person-centred approach may require a single appointment, when necessary investigations and examination are undertaken and the individual may see the practice nurse and then the doctor for reasonable amounts of time e.g. half an hour each. A template, such as the Cardiff Health Check Template (see resources below for the link), as well as the use of prompts for syndrome-specific health checks e.g. for those with Down's syndrome or Fragile X syndrome (Hoghton, 2010). If the person is unable to communicate pain, an assessment tool, such as the Disability Distress Assessment Tool (DisDAT), should be used (Regnard et al., 2006).

An assessment of feeding, bowel and bladder function, behavioural disturbance, and vision and hearing can be included in the review of pre-existing chronic disease. (Chauhan, Kontopantelis, Campbell, Jarrett \& Lester, 2010). Consider using the Lester Positive Cardiometabolic Health Resource as a simple assessment and intervention framework to protect the cardiovascular and metabolic health of those receiving psychotropic medication (Lester, Shiers, Rafi, Cooper \& Holt, 2012). An individual's vulnerabilities and risk of abuse should also be assessed (Hoghton, 2010). 
Figure 2 provides a summary of main areas to consider for the annual health check.

\section{Insert Figure 2 here}

Immunisations and vaccinations are an important area of health promotion. Childhood immunisations should be given as per the general population. Human papilloma vaccination (HPV) is currently given to all girls aged 12-13 years old and is available on the NHS for any girl under 18 years. The Flu Plan prioritises people with intellectual disabilities as an at-risk group, and they should be vaccinated annually. Pneumococcal vaccination may also be considered. Tdap (tetanus, diphtheria and pertussis) vaccination is given to pregnant women at around 28 weeks gestation. Since September 12016 the shingles vaccination has been available on the NHS to those aged 70 and 78 years with eligibility for the vaccine falling on the first day of September 2016 after patients turn 70 or 78 and remain eligible until August 2017. Anyone who was eligible for immunisation but missed out remains eligible until their $80^{\text {th }}$ birthday. Due to a high prevalence of hepatitis B in people with intellectual disabilities in residential homes, vaccination is recommended (Public Health England, 2014). Table 1 summarises this.

\section{Insert Table 1}

\section{Conclusion}

People with intellectual disability experience increased morbidity and mortality. The Marmot Review (2010) argued for 'proportionate universalism' to address such inequality by 'the resourcing and delivering of universal services at a scale and intensity proportionate to the degree of need'. Whilst the intention may have been to apply this at the level of resource allocation and organisation, it may also be applied at clinician level for GP trainees and GPs to spend proportionately more time developing knowledge and skills to deal with people with intellectual disabilities and greater needs.

A key area for improving the health of people with intellectual disability is to improve the education and training of clinicians in dealing with people with intellectual disabilities (Gribben \& Bell, 2010). The RCGP provides links to emodules and there are a number of resources listed in Box 3. Furthermore, one could contact their local learning disability team for further specialist training.

\section{Insert Box 3 here}

\section{Key points}

- People with intellectual disability have much worse health outcomes than the general population, with a life expectancy for men and women thirteen and twenty years shorter, respectively. 
- GPs can improve the health of this population with improvements in professional education and training and enhanced provision of annual health checks, health promotion and screening.

- Mechanisms for improving the care of this population can be considered at an individual and organisational level.

- It is a legal requirement to make reasonable adjustments to ensure people with intellectual disability have access to the same level of services as the general population.

- There are a number of services available to support clinicians and primary care providers in improving the health of this population.

\section{References and further information}

Buszewicz M., Welch C., Horsfall L., Nazareth I., Osborn D., Hassioti A., Strydom A. (2014). Assessment of an incentivised scheme to provide annual health checks in primary care for adults with intellectual disability: a longitudinal cohort study, The Lancet Psychiatry; 1(7), 522-530

Carey, I.M., Shah, S.M., Hosking, F.J., DeWilde, S., Harris, T., Beighton, C., Cook, D.G., (2016). Health characteristics and consultation patterns of people with intellectual disability: a cross-sectional database study in English general practice, British Journal of General Practice; DOI: 10.3399/bjgp16X684301

Chauhan, U., Kontopantelis E., Campbell S., Jarrett H. \& Lester H. (2010) Health checks in primary care for adults with intellectual disabilities: how extensive should they be? Journal of Intellectual Disability Research; 54(6), 479-486

Department of Health. (2001). Valuing People: A New Strategy for Learning Disability for the 21st Century. Retrieved from www.gov.uk/government/uploads/system/uploads/attachment data/file/2508 77/5086.pdf

Department of Health. (2005). Mental Capacity Act. Retrieved from www.legislation.gov.uk/ukpga/2005/9/contents

Department of Health. (2012). Transforming care: A national response to Winterbourne View Hospital. Retrieved from www.gov.uk/government/uploads/system/uploads/attachment data/file/2132 15/final-report.pdf

Emerson E., Baines S., Allerton L. \& Welch V. (2012). Health Inequalities and People with learning disabilities in the UK: 2012. Improving Health and Lives Learning Disabilities Public Health Observatory. Retrieved from www.improvinghealthandlives.org.uk/securefiles/160615 0203//IHAL\%20201 2-11\%20Health\%20Inequalities r1.pdf

Emerson E. \& Hatton C. (2004). Estimating the Current Need / Demand for Supports for People with Learning Disabilities in England. Institute for Health 
Research, Lancaster University. Retrieved from www.improvinghealthandlives.org.uk/uploads/doc/vid 7008 Estimating Curre nt Need Emerson and Hatton 2004.pdf

General Medical Council (GMC). (2016). Into Practice: Tips for doctors. Retrieved from www.gmc-uk.org/learningdisabilities/302.aspx

Government Equalities Office. (2010). The Equality Act 2010. Retrieved from www.legislation.gov.uk/ukpga/2010/15/contents

Gribben K. \& Bell M. (2010). Improving equality of access to cervical screening. Learning Disability Practice; 13(7)

Heslop P., Blair P.S., Fleming P., Hoghton M., Marriott M. \& Russ L. (2014). The Confidential Inquiry into premature deaths of people with intellectual disabilities in the UK: a population-based study. The Lancet; 383(9920), 889-895

Hoghton M. (2010). Step by Step Guide for GP Practices: Annual Health Checks for People with a Learning Disability. Retrieved from www.rcgp.org.uk/learningdisabilities/ /media/Files/CIRC/CIRC-7680/CIRCA\%20StepbyStepGuideforPracticesOctober\%2010.ashx

Lester H, Shiers D, Rafi I, Cooper S, Holt R (2012). Positive Cardiometabolic Health Resource: An Intervention Framework for Patients with Psychosis on Antipsychotic Medication. Royal College of Psychiatrists. Retrieved from www.rcpsych.ac.uk/quality/nationalclinicalaudits/schizophrenia/nationalschiz ophreniaaudit/nasresources.aspx

London Deanery (2012): Multiprofessional Faculty Development: Institutional Discrimination. Retrieved from www.faculty.londondeanery.ac.uk/e-learning/diversity-equal-opportunitiesand-human-rights/institutional-discrimination

Marmot M. (2010). Fair Society, Healthy Lives. A Strategic Review of Inequalities in England. Retrieved from

www.instituteofhealthequity.org/Content/FileManager/pdf/fairsocietyhealthyli ves.pdf

Mason J \& Scior K (2004). Diagnostic Overshadowing' Amongst Clinicians Working with People with Intellectual Disabilities in the UK Journal of Applied Research in Intellectual Disabilities; 17(2) 85-90

Mencap (2007) Death by Indifference Report about institutional discrimination within the NHS, and people with a learning disability getting poor healthcare. Retrieved from www.mencap.org.uk/document.asp?id=284

NHS England \& BMA. (2015). General Medical Services Contract 2014/15 Gudance and Audit Requirements. Retrieved from www.nhsemployers.org/case- 
studies-and-resources/2014/08/201415-general-medical-services-contractquality-and-outcomes-framework

Osborn DPJ, Horsfall L, Hassiotis A, Petersen I, Walters K, Nazareth I. (2012). Access to Cancer Screening in People with Learning Disabilities in the UK: Cohort Study in the Health Improvement Network, a Primary Care Research Database. PLoS ONE 2012; 7

Perez W. (2002) Top Ten Tips for Effective Consultation. Retrieved from www.intellectualdisability.info/changing-values/articles/top-ten-tips-foreffective-consultation

Public Health England (2014). The Green Book. Chapter 18 Hepatitis B. Retrieved from www.gov.uk/government/uploads/system/uploads/attachment data/file/5037 68/2905115 Green Book Chapter 18 v3 0W.PDF

Public Health England (2014) The Uptake of Learning Disability Health Checks. Retrieved from www.improvinghealthandlives.org.uk/securefiles/160531 2042//Learning\%20 disability $\% 20$ health $\% 20$ checks $\% 20$ report $\% 202014 . p d f$

RCGP. Clinical module 3.11: Care of People with Intellectual Disability. Retrieved from www.rcgp.org.uk/training-exams/gp-curriculumoverview/online-curriculum/managing-complex-care/3-11-intellectualdisability.aspx

Regnard C, Reynolds J, Watson B, Matthews D, Gibson L, Clarke C. (2006). Understanding distress in people with severe communication difficulties: developing and assessing the Disability Distress Assessment Tool (DisDAT). Journal of Intellectual Disability Research; 51

Sheehan R., Hassiotis A., Walters K., Osborn D., Strydom A., Horsfall L. (2015). Mental illness, challenging behaviour, and psychotropic drug prescribing in people with intellectual disability: UK population based cohort study BMJ; 351: h4326

Stedman K.V. \& Leland L.S. (2010) Obesity and intellectual disability in New Zealand. 35(2), 112-115.

Thompson S.G., Ashton H.A., Gao L. \& Scott R.A.P. (2009). Screening men for abdominal aortic aneurysm: 10 year mortality and cost effectiveness results from the randomised Multicentre Aneurysm Screening Study. BMJ; 338:b2307

Truesdale-Kennedy M., Taggart L. \& Mcilfatrick S. (2011). Breast cancer knowledge among women with intellectual disabilities and their experiences of receiving breast mammography. Journal of Advanced Nursing; 67(6), 12941304. 
Turner, S., Giraud-Saunders A. \& Marriott A. (2013). Improving the uptake of screening services by people with learning disabilities across the South West Peninsula: a strategy and toolkit. Retrieved from

www.ndti.org.uk/uploads/files/Screening Services Strategy Toolkit final.pdf

Figure 1: Barriers to health care.

\section{Barriers to health care Interpersonal Organisational}

Diagnostic Overshadowing

- Physical(and mental) heath viewed as part of intellectual disability

- Lack of cl inical knowledge and confidence

- poor communication skills: Over reliance on verbal communication for diagnosis

- Prognostic pessimism: There is nothingyou can do to improvecare
Institutional Discrimination

- Inaccessble Environment:

No adjustments to wating area, consultation length, for example

- Inaccessble information: No provision of information in a format appropriate to need: easy read, pictorial or oral.

- Inaccessbletransport

- Segmented Services: Poor interface between primary care and specialist care 
Figure 2: Annual health checks.

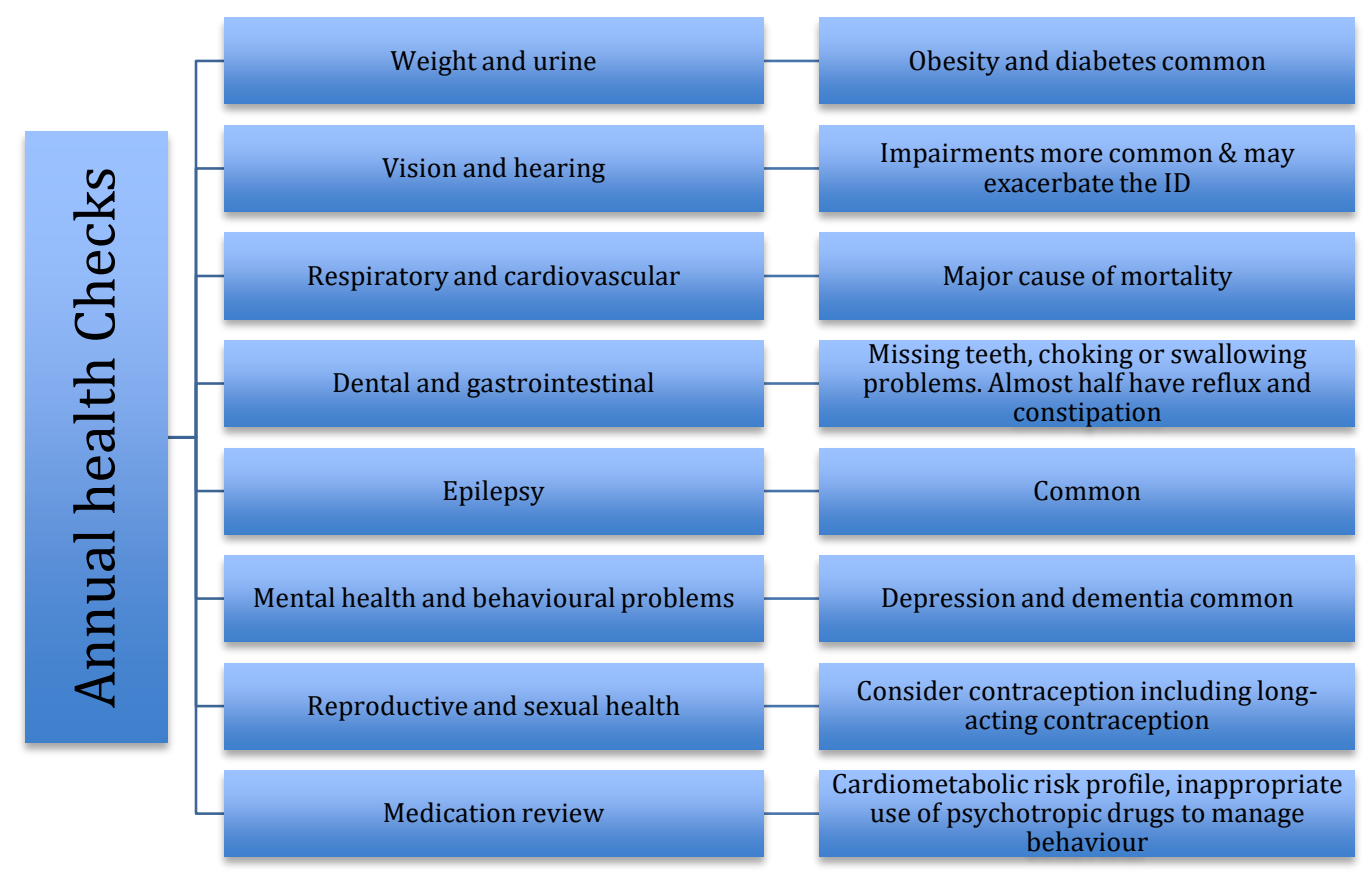


Table 1: Immunisation schedule for intellectual disability.

\begin{tabular}{|l|l|}
\hline Immunisations & When given \\
\hline & \\
\hline Childhood immunsations & $\begin{array}{l}\text { As per general population (including } \\
\text { HPV) }\end{array}$ \\
\hline Tdap & Pregnancy \\
\hline Influenza & Annually \\
\hline & $\begin{array}{l}\text { Consider if indicated as a single dose } \\
\text { of pneumococcal polysaccharide } \\
\text { vaccine 23 (PPV23) }\end{array}$ \\
\hline Pneumococcus & If in residential home \\
\hline Shingles & $\begin{array}{l}\text { As per general population (aged 70- } \\
79 \text { years) }\end{array}$ \\
\hline
\end{tabular}

Box 1: Perez's top tips for effective consultations with people with intellectual disabilities. (Adapted from Perez 2002).

1) Offer someone with intellectual disabilities the first appointment.

2) Offer a longer consultation time e.g. double appointments

3) Address the person with intellectual disabilities first. Then clarify any details with the accompanying carer.

4) Use open questions. Try changing the question format to see if you get the same response.

5) Explain what you are going to do at the start of the meeting.

6) Use simple language and consider communication aids e.g. pictures.

7) Carers may offer some useful information.

8) Check the person has understood by asking them to explain in their own words.

9) When talking about time, referring to events may be more understandable e.g. 'before going to bed' as opposed to 'at night time'.

10) Do not assume the person will be able to connect the illness to their actions or an event that has happened. 


\section{Box 2: Assessing Capacity: CURB.}

C - Communicate. Can the person communicate their decision?

$\mathrm{U}$ - Understand. Can they understand the information you giving them?

$\mathrm{R}$ - Retain. Can they retain the information given to them?

B - Balance. Can they balance or use the information?

Adapted from General Medical Council, 2016

\section{Box 3: Further Information.}

The RCGP website has a number of useful links for further information: www.rcgp.org.uk/training-exams/gp-curriculum-overview/onlinecurriculum/managing-complex-care/3-11-intellectual-disability/3-11-learningresources.aspx

The Cardiff Health Check Template is a useful resource when seeing the patients: www.rcgp.org.uk/ /media/Files/CIRC/Learning\%20disabilities/CardiffHealthC heck\%20Template\%202.ashx

Improving Health And Lives (IHAL) contains a vast array of public health information regarding intellectual disability.

www.improvinghealthandlives.org.uk

Easyhealth contains easy to read information.

www.easyhealth.org.uk

The British Institute of Learning Disabilities (BILD) works with organisations and supports people with intellectual disabilities.

www.bild.org.uk

Mencap is an organisation active in advocacy of people with intellectual disabilities.

www.mencap.org.uk

There are a number of useful online modules to increase knowledge such as: www.e-lfh.org.uk/programmes/general-practitioners

The Challenging Behaviour Foundation provides advice on dealing with behavioural challenges in intellectual disability. www.challengingbehaviour.org.uk 